\title{
The Effect of Aggregate Types on the Properties of Concrete
}

\author{
Balteh Mohammed ${ }^{1}$, Ebenehi Ibrahim Yakubu ${ }^{1}$, Shuaibu Nuru Mamman ${ }^{1}$, \\ Muhammad Nda ${ }^{2}$, Adamu Abdullahi Ayni ${ }^{3}$, Mukaila Zakari ${ }^{1}$, Bello Kabir ${ }^{1}$
}

${ }^{1}$ The Federal Polytechnic Bauchi

Bauchi-Tafawa Road, 740102, Bauchi, Nigeria

${ }^{2}$ The Federal Polytechnic, Bida

KM 1.5, Doko Road, Bida, Niger State, Nigeria

${ }^{3}$ Kogi State Polytechnic Lokoja

P. M. B. 101, Lokoja, Nigeria

DOI: $10.22178 /$ pos.77-3

LCC Subject Category:

TH1000-1725

Received 20.11.2021

Accepted 28.12.2021

Published online 31.12.2021

Corresponding Author:

Ebenehi Ibrahim Yakubu

iyebenehi@gmail.com

(C) 2021 The Authors. This article is licensed under a Creative Commons Attribution 4.0 License @ (1)
Abstract. Concrete is an extensively used construction material due to its versatility, strength, durability, and ease in making various forms and shapes. The use of substandard materials, deficient quality concrete has been identified in the literature as the leading cause of building collapse in Nigeria. Aggregates strongly affect the concrete's fresh and hardened properties, mixture proportions, and economy. More than $1 / 3$ of the volume of concrete is occupied by the coarse aggregate, and any changes in rough aggregate type could affect its strength and fracture properties. This study examined the impact of coarse aggregates on the mechanical properties of concrete. Selected aggregates which are granite (igneous rock), schist (metamorphic rock), and sandstone (sedimentary rock), were used in this study. Aggregate Impact value and water absorption test were carried out for each of the aggregates used. A slump test was conducted on the fresh mixture for granite, schist, and coarse sandstone aggregates with river sand (fine aggregate) using a water-cement ratio of 0.50 ; it was observed that granite has a slump value of $35 \mathrm{~mm}$, schist $28 \mathrm{~mm}$, and sandstone $25 \mathrm{~mm}$. Nominal mix (1:2:4) was adopted, and mix compositions were calculated using the absolute volume method. Twelve cubes $(100 \times 100 \mathrm{~mm})$ and twelve cylinders $(100 \times 300 \mathrm{~mm})$ were cast for each type of coarse aggregate. The specimens were cured by submersion. Three of the models were tested for $7,14,21$, and 28 days to determine their compressive and splitting tensile strengths. Granite was found to have the highest average compressive strength of $16.00 \mathrm{~N} / \mathrm{mm}^{2}$ with an average density of $2575 \mathrm{~kg} / \mathrm{m}^{3}$, compressive strength of schist was $15.17 \mathrm{~N} / \mathrm{mm}^{2}$ with an average density of $2520 \mathrm{~kg} / \mathrm{m}^{3}$, while sandstone has the lowest average compressive strength of $12.33 \mathrm{~N} / \mathrm{mm}^{2}$ with an average density of $2500 \mathrm{~kg} / \mathrm{m}^{3}$. Granite was found to have the highest moderate splitting tensile strength of 1.31 $\mathrm{N} / \mathrm{mm}^{2}$ with an average density of $4266.67 \mathrm{~kg} / \mathrm{m}^{3}$, breaking tensile strength of schist was $0.99 \mathrm{~N} / \mathrm{mm}^{2}$ with an average density of $4256.67 \mathrm{~kg} / \mathrm{m}^{3}$.

In contrast, sandstone has the lowest average split tensile strength of $0.67 \mathrm{~N} / \mathrm{mm}^{2}$ with an average density of $4241.67 \mathrm{~kg} / \mathrm{m}^{3}$. Densities and stability of the individual aggregates accounted for the variation in the concrete forces because of differences in properties and strength. In conclusion, the effect of coarse aggregate on the properties of concrete was identified, which will inform site concrete production of the suitability of aggregate selection in concrete work.

Keywords: aggregates; concrete; construction materials.

\section{INTRODUCTION}

Concrete is a complex material comprising cement, fine aggregate (sand), coarse aggregate (gravel or granite) and water in a certain prescribed proportion. The strength of concrete mix is dependent on many parameters like cement type, coarse aggregate and the interface between 
aggregate and mortar. Authors [1] stated that assessing concrete aggregate is vital to overcome the problem of structural collapse due to concrete failure in a particular environment. The aggregates within the mixture provide a rigid skeletal structure and reduce the space occupied by the cement paste. The proportions of various sizes of coarse aggregate mainly vary depending on the particular mix required for each end-use.

Coarse aggregate plays a vital part in concrete. The total typically occupies more than one-third of the volume of concrete, and research indicates that changes in coarse aggregate can change the strength and fracture properties of concrete. Concrete can be seen as a multi-phase composite material consisting of the mortar, mortar/aggregate interface, and coarse aggregate phase. The coarse aggregate in regular concrete is mainly from rock fragments characterized by high strength $[2,3]$.

Several researchers have identified the use of substandard materials, particularly in concrete production, as the leading cause of building collapse in Nigeria $[4,5]$. The beginning of failure is manifested by crack growth in the concrete. The crack grows mainly around the cement paste or at the aggregate/cement paste interfacial zone for regular concrete. The intensity of concrete at the interfacial area fundamentally depends on the reliability of the cement paste, and the kind of coarse aggregate used [6].

The use of crushed quartzite, crushed granite, limestone, and marble as coarse aggregate affected the mechanical properties of concrete. The concrete's strength, stiffness, and fracture energy for a specified water/cement ratio depended on the aggregates category [7]. Authors [8] posited that the compressive strength of concrete is dependent on the aggregate used. Authors [9] stated that aggregates are expected to have significant effects on the properties of concrete since they occupy $70-80 \%$ of it. Concrete aggregates and paste are the crucial factors affecting concrete's strength $[9,10]$. The aggregate properties significantly affect concrete durability, and structural performance as aggregate with undesirable properties cannot produce strong concrete [11]. This project investigates the effects of various coarse aggregates on the mechanical properties of fresh and hardened concrete.

This research seeks to examine the impact of aggregate type on concrete properties.
The research was achieved with the aid of the following objectives:

1. To determine the effect of aggregates type on the mechanical properties of fresh concrete.

2. To determine the effect of aggregates type on the mechanical properties of hardened concrete.

3 . To determine the properties of the selected aggregates regarding moisture absorption and impact resistance.

\section{Significance and Limitation of the Study}

This study was undertaken to determine the properties of conventional concrete produced from different types of coarse aggregate at the fresh and hardened stage. The research seeks to assess the coarse aggregates most suitable for construction works. The study's outcome reveals the effect of aggregate types in concrete production and some of the characteristics of the selected aggregates. The study seeks to discourage substandard materials for different construction purposes, especially coarse aggregates of undesirable traits.

This research is limited to some selected aggregates. It focuses mainly on the following laboratory test: slump test, compressive strength test, aggregate impact test, and split tensile strength test. Other tests, such as the compacting factor test, soundness, shrinkage, modulus of elasticity etc., were not conducted.

\section{Review of Previous Studies}

Several investigations have been conducted to study the effect of changing aggregate type in concrete production towards enhancing the mechanical properties of fresh and hardened concrete. Authors [12] determined the influence of different types of aggregate (quartzite, dolomite, limestone) on concrete performance. Dolomite was found to be aggregate with optimum performance in concrete production. It was concluded that aggregate gradation for optimum previous concrete strength should be monitored. Similarly, the influence of dolomite and steel slag was studied [13]. The research concluded that the type of aggregate affects density, porosity and strength more than aggregate size. According to [14], the physical properties of aggregate, such as the size, shape, and particles distribution, influence concrete's mechanical and hydraulic properties. However, the aggregate type was the most 
significant factor affecting the strength of concrete produced. Authors [15] examined the impact of coarse aggregates type on the compressive strength of concrete. According to their findings, concrete made from quartzite aggregate had the highest compressive strength. With a compression strength of $24.48 \mathrm{~N} / \mathrm{mm}^{2}$ and a density of $2.16 \mathrm{~kg} / \mathrm{m}^{3}$, quartzite had the highest average compressive strength.

In contrast, that of Crushed Granite was $22.01 \mathrm{~N} / \mathrm{mm}^{2}$ with an average density of $2.30 \mathrm{~kg} / \mathrm{m}^{3}$ on the 28 days of testing. This demonstrates that neither aggregate (crushed granite nor quartzite) could meet the required strength of $30 \mathrm{~N} / \mathrm{mm}^{2}$ for concrete production. They concluded that the factors responsible for the variation in concrete strength are the properties of the different aggregates (densities and compressive forces) due to differences in properties and strengths

In his research, [6] stated that aggregate type has a significant effect on the strength of standard concrete. At his conclusion, he suggested that crushed quartzite aggregate may be employed for concrete work in places where concrete practitioners have various choices available. Authors [6] look into the effects of different types of coarse aggregate on the multiple properties of concrete. Based on the papers on the subject, a try was made to identify the impact of different kinds of total on the various mechanical properties like compressive strength, modulus of elasticity, tensile strength, flexural strength and the mortar-aggregate bond. Their review concluded that; In high strength concrete, the compressive strength is affected by the aggregate used, whereas, in regular strength concrete, compressive strength is independent of aggregate type. Stiffer aggregates will produce a stiffer concrete mix. Modulus of elasticity mainly depends on the mortar aggregate interface, which is further dependent on the aggregate strength for highstrength concrete. Tensile strength of aggregate is independent of the total used and is significantly affected by the surface characteristic of the full.

\section{MATERIALS AND METHODS}

Timber moulds (100x100x100 mm) were used. The moulds were oiled to facilitate easy demoulding of the hardened concrete. Cylinders (100 mm x $300 \mathrm{~mm}$ ) were cast using PVC pipes cut to the specified sizes. A total number of
36 cubes and 36 cylinders were released. After launching, the specimens were numbered for easy identification and demoulded after 24 hours. The composition of the materials used for this work includes aggregates (coarse aggregate and fine aggregates), ordinary Portland cement and water.

Aggregate is essential because it occupies about three-quarters of the volume of concrete [16]. Usually, two types of total are used in concrete: delicate and coarse aggregates. Many parameters need to be considered in selecting sum, for instance, types of aggregate, size and shape of the particle, and the strength of the aggregate. All aggregate must be free from dust as the dust may affect the bonding between the total and cement particles.

The fine aggregates are responsible for filling all the gaps between the coarse particles. As a result, it reduces the porosity of the final mass while significantly increasing its strength. The fine aggregate used in this investigation is river sand.

The coarse aggregates are used as filler with binding material in concrete production. They are derived from igneous, sedimentary and metamorphic rocks or manufactured from blast furnace slag [17]. Crushed stone with the largest size of $20 \mathrm{~mm}$ was used as coarse aggregate in this study. Three different types of coarse aggregate were used, namely: granite (which is a variant of igneous rock), marble (a variant of metamorphic rock) and sandstone (a variant of sedimentary rock).

Granite is a coarse-grained igneous rock composed primarily of quartz, alkali feldspar and other minerals in minor composition. It is the best-known igneous rock and is considered the most common type of igneous rock.

Sandstone is a sedimentary rock composed of sand-size grains of minerals, gravel, or organic materials. It also contains cementing materials that bind the sand grains together. It is considered the most common type of sedimentary rock.

Schist is a metamorphic rock that contains lamellar minerals such as muscovite, biotite and chlorite. It has medium to light large, flat, sheet-like grains in a preferred orientation, mostly parallel. Its application in building ranges from structural to decorative purposes. 
In addition, the aggregates were cleaned before mixing to wash away the fine particles that stick on the surface of the sum.

Cement. A $50 \mathrm{~kg}$ of ordinary Portland cement (Dangote 3X brand, grade $32.5 \mathrm{R}$ ) was used as the binding agent for this experiment. The expected strength of concrete cannot be achieved without adequate cement. The cement, therefore, was used to provide the required matrix between the materials in the presence of mixing water for the chemical process (hydration) in which the cement powder sets and hardens into a solid mass.

Water. Cement will always remain inert in providing a matrix between the materials, except there is water needed for the required mixing, ease of placement, consistency and workability. The water used for this experiment was clean and drinkable. The presence of impurities will reduce targeted strength due to a reduction in the effectiveness of the bond. The source of water used for the work was healthy water.

\section{Source of Materials}

$50 \mathrm{~kg}$ bag of ordinary Portland cement (Dangote $3 \mathrm{X}$ brand) was purchased from the building material market in Bauchi. Fine aggregate was obtained from the civil engineering laboratory of the federal polytechnic Bauchi. The coarse aggregates were obtained from the Kofar Nassarawa quarry in Bauchi.

\section{Sieve Analysis}

Sieve analysis helps determine the particle size distribution of aggregates, both coarse and fine. This was done by sieving the aggregates as I.S.: 2386 (part I) 1963. Different sieve sizes as standardized by the I.S. code were used. The totals were poured into the sieve, and thus other sized particles left on each sieve were collected. This test was carried out to determine the particle size distribution of the fine and coarse aggregate to be used. The particles were subjected to surface drying at room temperature, and the sieves used were clean. The dried samples were weighed and sieved successively on appropriate sieves starting by shaking manually for 10 minutes. The materials retained on each sieve were considered (Table 1-3).
Table 1 - Sieve analysis of sand

\begin{tabular}{|c|c|c|c|}
\hline $\begin{array}{c}\text { Sieve size } \\
(\mathrm{mm})\end{array}$ & Retained & \multirow{2}{*}{$\%$} & $\begin{array}{c}\% \\
\text { passing }\end{array}$ \\
\cline { 2 - 2 } & Weight & & 90.86 \\
\hline $2.0 \mathrm{~mm}$ & 91.4 & 9.14 & 70.86 \\
\hline $1.18 \mathrm{~mm}$ & 200.0 & 20.00 & 73.0 \\
\hline $600 \mu \mathrm{m}$ & 430.0 & 43.0 & 27.86 \\
\hline $425 \mu \mathrm{m}$ & 136 & 13.6 & 14.26 \\
\hline $150 \mu \mathrm{m}$ & 127.5 & 12.75 & 1.51 \\
\hline $75 \mu \mathrm{m}$ & 11.006 & 0.11 & \\
\hline Pan & 4.0041 & 0.400 & \\
\hline Total & 1000 & 100 & \\
\hline
\end{tabular}

Table 2 - Sieve analysis of granite aggregate

\begin{tabular}{|c|c|c|c|}
\hline \multirow{2}{*}{ Sieve size $(\mathrm{mm})$} & Retained & \multirow{2}{*}{$\%$} & \multirow{2}{*}{$\%$ passing } \\
\cline { 2 - 3 } & Weight & & \\
\hline $25.0 \mathrm{~mm}$ & 140.0 & 14.00 & 85.50 \\
\hline $20.0 \mathrm{~mm}$ & 128.0 & 128.00 & 72.70 \\
\hline $14.0 \mathrm{~mm}$ & 432.5 & 43.25 & 29.45 \\
\hline $10.0 \mathrm{~mm}$ & 53 & 53.00 & 24.15 \\
\hline Pan & 246.5 & - & - \\
\hline Total & 1000 & 100 & \\
\hline
\end{tabular}

Table 3 - Sieve analysis of schist aggregate

\begin{tabular}{|c|c|c|c|}
\hline \multirow{2}{*}{ Sieve size $(\mathrm{mm})$} & Retained & \multirow{2}{*}{$\%$} & \multirow{2}{*}{$\%$ passing } \\
\cline { 2 - 3 } & Weight & & \\
\hline $25.0 \mathrm{~mm}$ & 160.0 & 16.00 & 84.00 \\
\hline $20.0 \mathrm{~mm}$ & 148.0 & 14.80 & 69.20 \\
\hline $14.0 \mathrm{~mm}$ & 402.5 & 40.25 & 28.95 \\
\hline $10.0 \mathrm{~mm}$ & 73 & 7.30 & 21.65 \\
\hline Pan & 216.5 & - & - \\
\hline Total & 1000 & 100 & \\
\hline
\end{tabular}

Table 4 -Sieve analysis of sandstone aggregate

\begin{tabular}{|c|c|c|c|}
\hline \multirow{2}{*}{ Sieve size $(\mathrm{mm})$} & Retained & \multirow{2}{*}{$\%$} & \multirow{2}{*}{$\%$ passing } \\
\cline { 2 - 3 } & Weight & & \\
\hline $25.0 \mathrm{~mm}$ & 146.0 & 14.60 & 85.40 \\
\hline $20.0 \mathrm{~mm}$ & 138.0 & 13.80 & 71.60 \\
\hline $14.0 \mathrm{~mm}$ & 390.0 & 39.00 & 32.60 \\
\hline $10.0 \mathrm{~mm}$ & 65.0 & 6.50 & 26.10 \\
\hline Pan & 231.0 & - & - \\
\hline Total & 1000 & 100 & \\
\hline
\end{tabular}

The apparatus used for this experiment include; an aggregate impact testing machine with a standard tamping rod, an I.S. test sieve of size range between $16 \mathrm{~mm}$ aperture to $2.40 \mathrm{~mm}$ aperture and a weighing balance. Sample of each of the three coarse aggregates passing through the $12 \mathrm{~mm}$ I.S. test sieve and retained on $10 \mathrm{~mm}$ I.S. 
sieve was prepared. The $7.6 \mathrm{~cm}$ cylinder was filled in 3 equal layers giving 25 strokes using a tamping rod to compact it and level. The entire sample was placed in a cup securely attached to the impact machine's base, and 15 blows were applied to the cup by enabling the hammer to fall freely. The crushed aggregate was sieved using the $2.40 \mathrm{~mm}$ sieve and the percentage passing by weight was determined.

$$
A I V=\frac{M_{2}}{M_{1}} \times 100
$$

where $M_{1}$ represents the mass of the sample before impact and $\mathrm{M}_{2}$ is the mass of particles sieved on a $2.40 \mathrm{~mm}$ sieve.

The water absorption is measured by the difference in weight between the samples in a saturated dry condition and that in the oven-dry state expressed as a percentage of dry weight BS 1881 part 122 [18]. Water absorption for the samples was obtained by drying the samples in an oven to a constant temperature, after which they were then immersed in water for 24 hours. The difference in weight was obtained, and the water adsorption was calculated as follows:

$$
\text { Water absorption }=\frac{M_{2}-M_{1}}{M_{1}} \times 100
$$

where $\mathrm{M}_{1}$ - Dry weight of sample and $\mathrm{M}_{2}$ - Saturated weight of the sample

\section{DESIGN}

Calculations for the number of materials required for the experiment were done using batching by volume in the ratio of 0.50 for water, 1:2:4 for cement, fine aggregate and coarse aggregates, respectively. The Absolute Volume Method was employed to calculate the volumes of materials needed for the experiment, which adopts that the volume of compacted concrete equals the sum of the absolute volumes of the ingredients. It can be expressed using the equation below:

$$
\text { Absolute Volume }=\frac{\text { Weight ofmaterial }}{\text { Material specific gravity }}(3)
$$

The results of the calculations are shown below.

Table 5 - Calculation of Materials/ $\mathrm{m}^{3}$

\begin{tabular}{|c|c|c|}
\hline Test & $(100 \times 100 \times 100) \mathrm{mm}$ Cubes & $\left(\pi r^{2} h\right) \mathrm{mm}$ \\
\hline Number of samples & 12 & 12 \\
\hline Vol. required per sample & $0.001 \mathrm{~m}^{3}$ & $0.0024 \mathrm{~m}^{3}$ \\
\hline Total vol. required & $0.0012 m^{3}$ & $0.0288 \mathrm{~m}^{3}$ \\
\hline Add 5\% waste & $0.0126 m^{3}$ & $0.0302 \mathrm{~m}^{3}$ \\
\hline Cement & $3.9 \mathrm{~kg}$ & $9.41 \mathrm{~kg}$ \\
\hline Sand & $8.845 \mathrm{~kg}$ & $21.20 \mathrm{~kg}$ \\
\hline Stones & $16.05 \mathrm{~kg}$ & $38.48 \mathrm{~kg}$ \\
\hline Water & $1.96 \mathrm{~kg}$ & $4.70 \mathrm{~kg}$ \\
\hline
\end{tabular}

\begin{tabular}{|l|c|c|c|c|}
\hline Material & $\begin{array}{c}\text { Specific } \\
\text { Gravity }\end{array}$ & $\begin{array}{c}\text { Bulk Density } \\
\left(\mathrm{Kg} / \mathrm{m}^{3}\right)\end{array}$ & $\begin{array}{c}\text { Mix 1:2:4 @ 0.50 } \\
\text { Water/Cement Ratio (litres) }\end{array}$ & $\begin{array}{c}\text { Quantity/ } \mathrm{m}^{3} \text { of Concrete } \\
(\mathrm{Kg})\end{array}$ \\
\hline Cement & 3.15 & 1440 & $(1440 / 3.15) \times 1=457$ & $(1440 / 4.621) \times 1=311.62$ \\
\hline Sand & 2.6 & 1622 & $(1622 / 2.6) \times 2=1247$ & $(1622 / 4.621) \times 2=702$ \\
\hline Stones & 2.68 & 1472 & $(1472 / 2.68) \times 4=2197$ & $(1472 / 4.621) \times 4=1274.18$ \\
\hline Water & - & - & $1440 \times 0.50=720$ & $(1440 / 4.842) \times 0.50=155.81$ \\
\hline \multicolumn{2}{l}{ Total absolute volume } & $4621=4.621 m^{3}$ litres & $2444=2.444$ \\
\hline
\end{tabular}

Table 6 - Quantity of Material Required for Cubes, and Cylinders 


\section{Mixing, casting and curing of the test specimen}

Before mixing, the required quantities for cement, fine aggregate, coarse aggregates and water for the batch were measured. Cement and fine aggregate were thoroughly mixed before adding the coarse aggregate and water. The mixing of these materials was undertaken by hand using a shovel and hand trowel, after which the required quantity of water was added. The combined constituents were then mixed thoroughly on a platform continuously until a workable, smooth, uniform and consistent mixture was obtained. The mixture was then poured into the moulds and compacted thoroughly; the excess mixture in the mould was then removed, and the top was smoothened using the hand trowel. The specimens were demoulded after 24 hours of casting and then placed in a curing tank filled with clean drinkable water for a period of 7, 14, 21, and 28 days respectively, as specified in BS 12390 part 2 [19].

Slump test. This test was carried out to determine the workability of the fresh concrete before casting the specimen BS EN 12350 part 2 [20]. The apparatus used for this experiment include:

1. Cone mould (bottom diameter $200 \mathrm{~mm}$, top diameter $100 \mathrm{~mm}$, height $300 \mathrm{~mm}$ )

2. Tamping rod

3. Steel plate

4. Measuring tape

5. Trowel

6. Measuring cylinder

The internal surface of the mould was cleaned thoroughly to make it free from superficial moisture and any set concrete before the test commenced. The mould was placed on a smooth, horizontal, non-absorbent surface firmly held against its base to restrict movement during the entire operation. It was filled in 3 layers, each approximately $1 / 3$ of its height. Each layer was tamped with 25 strokes of the round end of the tamping rod. After tamping the top layer, the mould was filled, and the excess concrete was struck off and finished with a trowel. The excess mortar, which leaked out between the mould and the base plate, was cleaned away. The mould was removed by raising it slowly and carefully vertically. The Slump was immediately measured by determining the difference between the height of the mould and the highest point of the specimen being tested. The slump measurement was recorded, and also the type of Slump was observed and noted.
Compaction of Concrete. For this experiment, compaction was done by hand using a tamping rod. Full compaction is an important parameter contributing to the strength and durability of concrete. Lack of adequate compaction can result to air voids which have a damaging effect on the strength and durability of the concrete. Compacting concrete aims to remove air, which is necessary to enhance stability. For every $1 \%$ of entrapped air, the power falls by somewhere between 5 and 7\%; this means that concrete containing a mere $5 \%$ air void due to inadequate compaction can lose as much as one-third of its strength.

\section{Strength of concrete specimen}

The concrete specimen's compressive strength and splitting tensile strength were determined using the crushing machine in the laboratory for 7, 14, 21 and 28 days curing age. Three cubes and three cylinders were crushed for each aggregate type, and the average was taken for each test, respectively.

BS 12390 part 3 [19] gives the concrete specimen strength test specifications. The compressive strength of the cubes was calculated using the formula below:

$$
\text { C. } S=\frac{P(N)}{A(m m 2)},
$$

where $\mathrm{P}$ is the applied load in $\mathrm{N}$, and $\mathrm{A}$ is the area of the cube in $\mathrm{mm}^{2}$

The splitting tensile strength of the cylinders was calculated using the formula below:

$$
\mathrm{T}=\frac{2 P(N)}{\pi L D(m m 2)},
$$

where $\mathrm{P}$ is the applied load, $\mathrm{L}$ is the length of the cylinder, and $\mathrm{D}$ is the diameter.

\section{RESULTS AND DISCUSSION}

The apparatus used include sieves, weighing balance, and scoop. Aggregates were cleaned and dried before sieving. The samples were sieved manually. The result is being expressed using the equation below and tabulated in the table. 
Sieve Analysis of Fine Aggregates Test Results. The sieve analysis test result was determined according to BS 882: Part 1973 Grading Limit for Fine
Aggregates. The results obtained are given below.

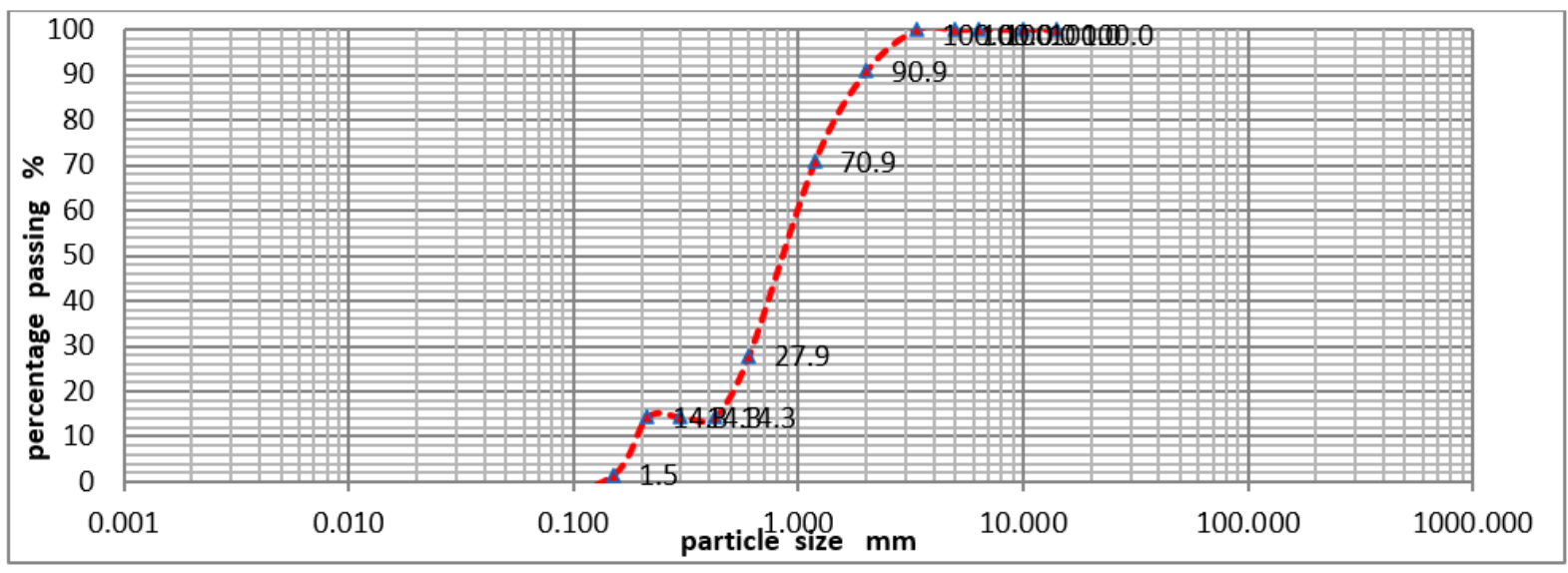

\begin{tabular}{|c|l|l|l|l|l|l|l|l|l|l|l|}
\hline \multirow{2}{*}{ CLAY } & Fine & Medium & Coarse & Fine & Medium & Coarse & Fine & Medium & Coarse & COBBLES & $\begin{array}{l}\text { BOUL } \\
\text { DERS }\end{array}$ \\
\cline { 2 - 7 } & \multicolumn{3}{|c|}{ SILT } & \multicolumn{3}{|c|}{ SAND } & \multicolumn{3}{c|}{ GRAVEL } & & \\
\hline
\end{tabular}

Figure 1 - Showing the grading of the fine aggregate used

Sieve Analysis of Coarse Aggregates Test Results. The sieve analysis test result was determined according to BS 882: Part 1973 Grading Limit for
Coarse Aggregates. The results obtained are given below.
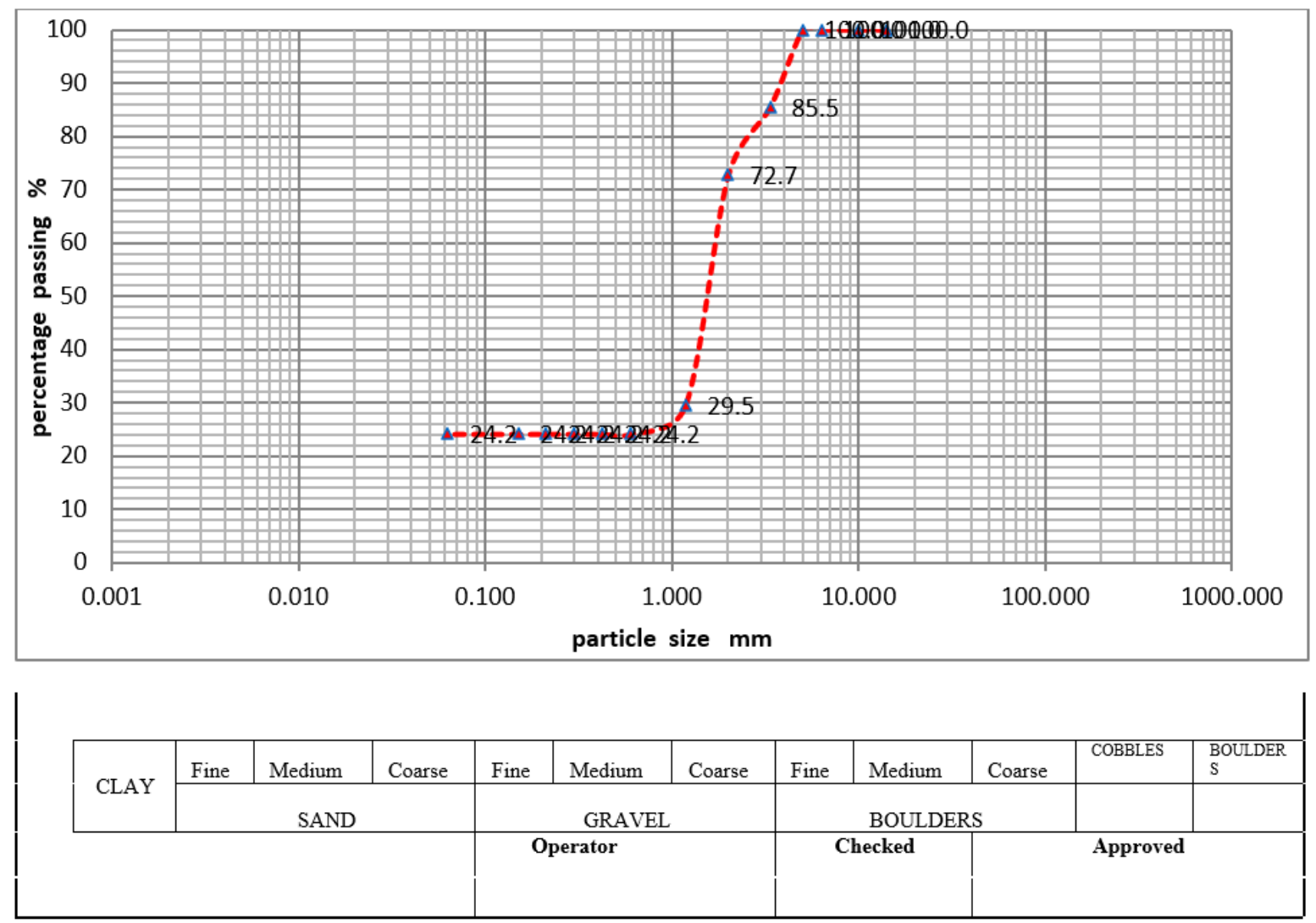

Figure 2 - The grading of the coarse aggregates used A) Sieve Analysis of granite 


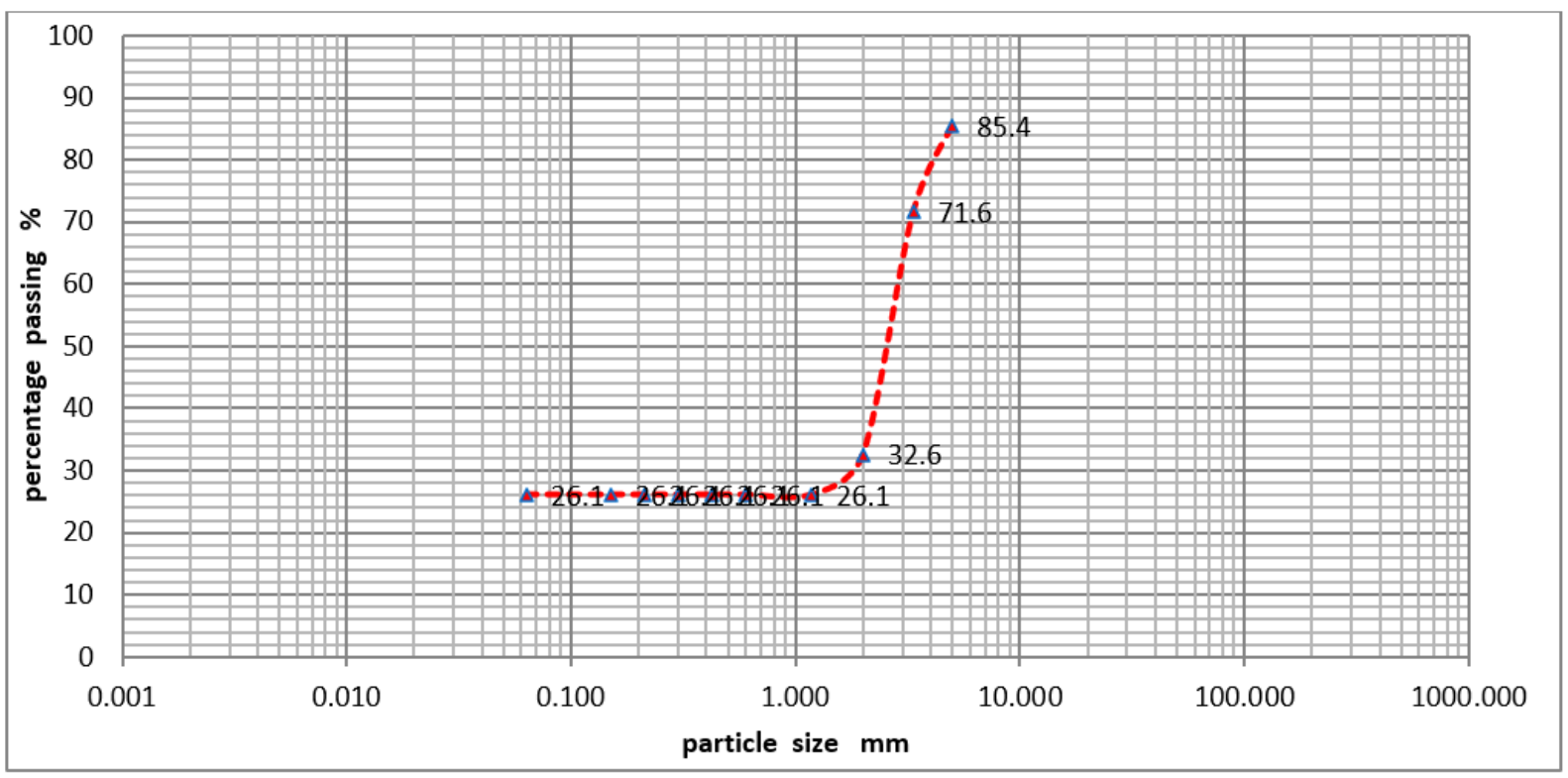

\begin{tabular}{|c|c|c|c|c|c|c|c|c|c|c|c|}
\hline \multirow{2}{*}{ CLAY } & Fine & Medium & Coarse & Fine & Medium & Coarse & Fine & Medium & Coarse & COBBLES & BOULDERS \\
\hline & \multicolumn{3}{|c|}{ SAND } & \multicolumn{3}{|c|}{ GRAVEL } & \multicolumn{3}{|c|}{ BOULDERS } & & \\
\hline & & & & \multicolumn{3}{|c|}{ Operator } & & lecked & \multicolumn{3}{|c|}{ Approved } \\
\hline
\end{tabular}

Figure 2 - The grading of the coarse aggregates used

B) Sieve analysis of schist
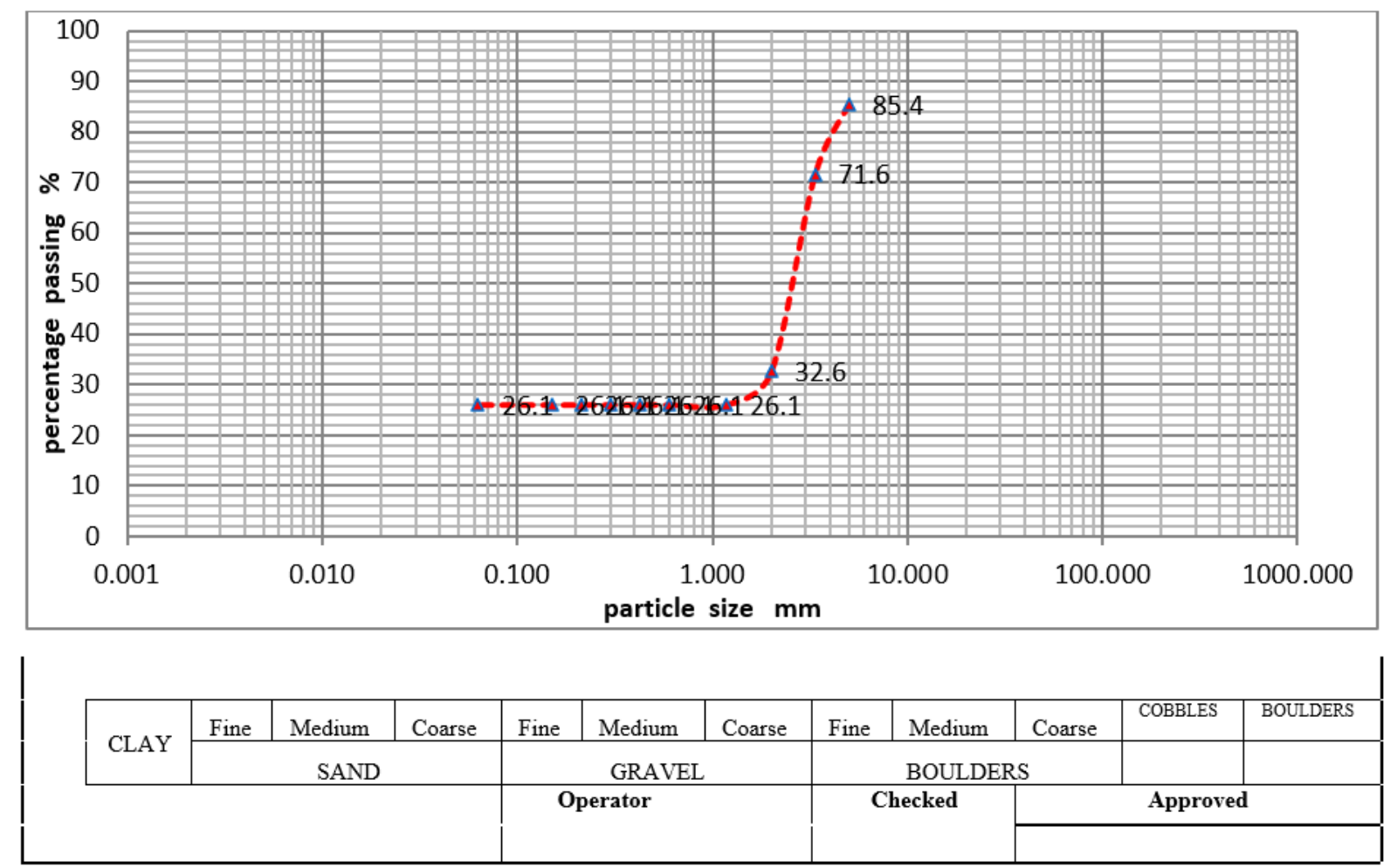

Figure 2 - The grading of the coarse aggregates used

C) Sieve analysis of sandstone 


\section{Aggregate impact value}

The aggregate Impact value test for each coarse aggregate was carried out. The $2.36 \mathrm{~mm}$ sieve size was used to sieve the specimen after impact, and the graph below shows the results as obtained.

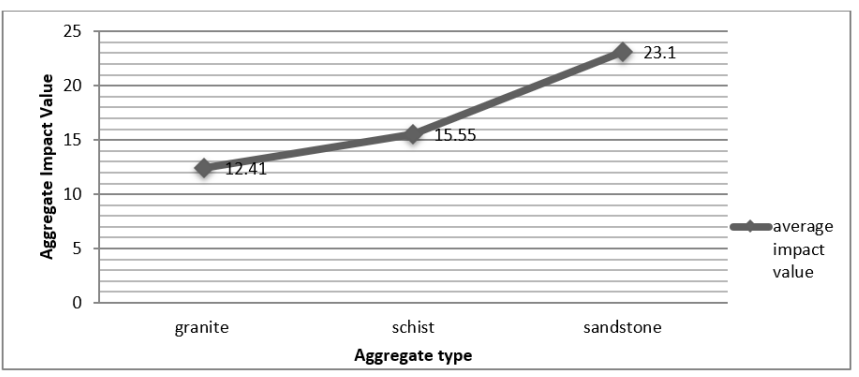

Figure 3 - The aggregate impact value for the different aggregate types

Table 7 - Aggregate impact value of coarse aggregates

\begin{tabular}{|l|l|l|l|l|}
\hline $\begin{array}{c}\text { Aggregate } \\
\text { type }\end{array}$ & Mass & Passing & $\begin{array}{c}\text { \% Of fine } \\
\text { passing }\end{array}$ & $\begin{array}{c}\text { Average } \\
\text { value }\end{array}$ \\
\cline { 2 - 5 } & Used & & 11.95 & \\
\hline Granite & 653 & 78 & 12.86 & 12.41 \\
\hline Granite & 653 & 84 & 12.55 & \\
\hline Schist & 653 & 95 & 14.55 & 15.55 \\
\hline Schist & 653 & 108 & 16.54 & \\
\hline Sandstone & 653 & 152 & 23.28 & \\
\hline Sandstone & 653 & 149 & 22.82 & 23.05 \\
\hline
\end{tabular}

\section{Aggregate water absorption}

The test on water absorption is as shown below. The test was carried out for the different aggregate samples (BS 1881 part 122 [21]). The aggregate produced from sedimentary rock (sandstone) was found to absorb water (moisture) more than the other aggregates (granite and schist). The results for aggregates moisture absorption are shown below.

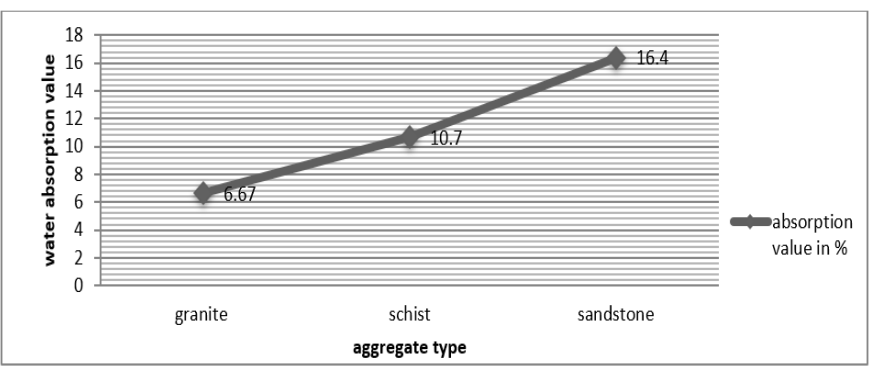

Figure 4 - The percentage (\%) of water absorption of the different aggregate types
Table 8 - Aggregate water absorption value

\begin{tabular}{|l|l|l|}
\hline Aggregate type & Values & \% of absorption \\
\hline Granite & 0.067 & 6.67 \\
\hline Schist & 0.107 & 10.70 \\
\hline Sandstone & 0.164 & 16.40 \\
\hline
\end{tabular}

\section{Workability}

The slump test result was essential in determining the workability of the concrete design. The design mix chosen was a regular slump concrete mix with a water/cement ratio of 0.50 . The water/cement ratio was selected to see the effects of the different aggregates used clearly and how they affected the concrete workability (BS EN 12350 part $2[20])$.

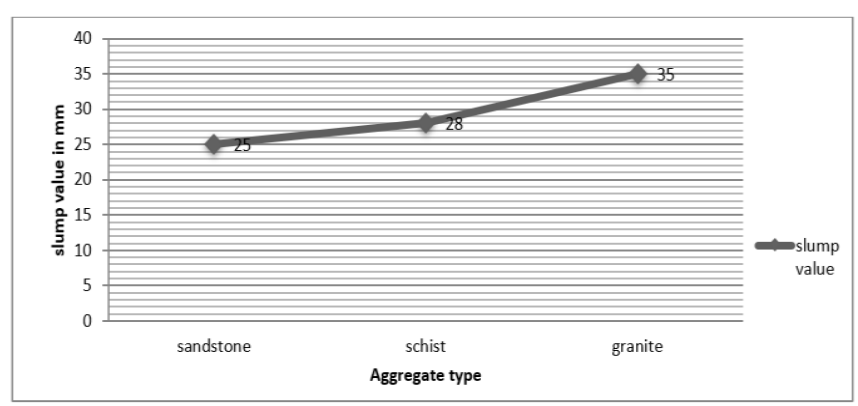

Figure 5 - The workability of fresh concrete produced with the different aggregates

Table 9 - Workability test

\begin{tabular}{|l|l|l|c|}
\hline $\begin{array}{c}\text { Water } \\
\text { cement ratio }\end{array}$ & $\begin{array}{c}\text { Aggregate } \\
\text { type }\end{array}$ & $\begin{array}{c}\text { Slump } \\
\text { type }\end{array}$ & $\begin{array}{c}\text { Slump } \\
\text { value(mm) }\end{array}$ \\
\hline 0.50 & Granite & $\begin{array}{l}\text { True } \\
\text { slump }\end{array}$ & 35.00 \\
\hline 0.50 & Schist & $\begin{array}{l}\text { True } \\
\text { slump }\end{array}$ & 28.00 \\
\hline 0.50 & Sandstone & $\begin{array}{l}\text { True } \\
\text { slump }\end{array}$ & 25.00 \\
\hline
\end{tabular}

\section{COMPRESSIVE TEST RESULTS}

The compressive strength for 7, 14 and 28 days was determined for the concrete cubes, as shown in the graph below (BS 12390 part 3 [22]). The results further certify the influence of the aggregate types on strength development in the concrete, and it was found to be within the range of the desired design strength. 


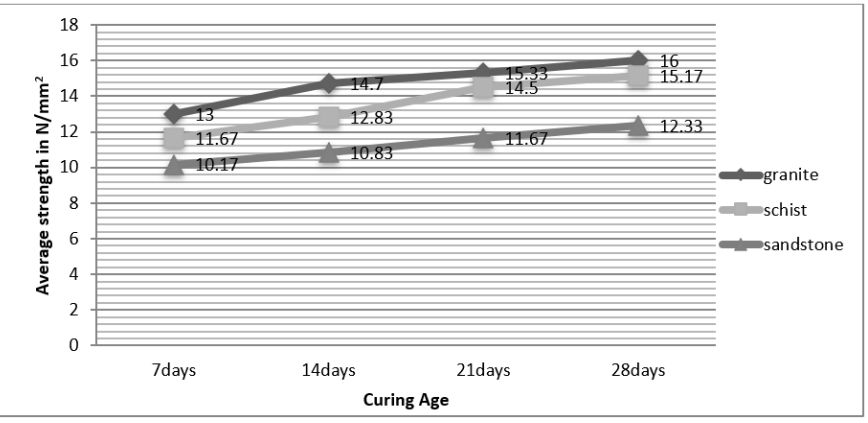

Figure 6 - Showing the average compressive strength at different curing ages

Table 10 - Compressive strength of concrete cubes $\left(\mathrm{N} / \mathrm{mm}^{2}\right)$

\begin{tabular}{|l|c|c|c|c|}
\hline $\begin{array}{l}\text { Aggregate } \\
\text { type }\end{array}$ & $\begin{array}{c}7 \\
\text { days }\end{array}$ & $\begin{array}{c}14 \\
\text { days }\end{array}$ & $\begin{array}{c}21 \\
\text { days }\end{array}$ & $\begin{array}{c}28 \\
\text { days }\end{array}$ \\
\hline Granite & 13 & 14.7 & 15.33 & 16 \\
\hline Schist & 11.67 & 12.83 & 14.50 & 15.17 \\
\hline Sandstone & 10.17 & 10.83 & 11.67 & 12.33 \\
\hline
\end{tabular}

\section{The density of concrete cubes}

The density of the concrete cubes was obtained by weighing 3 of the samples produced for each aggregate (ASTM C 138 [23]). The pieces were removed from the curing tank and left the surface dry for 30 minutes before weighing. The average weight of the sample was then taken, and the result is as shown below.

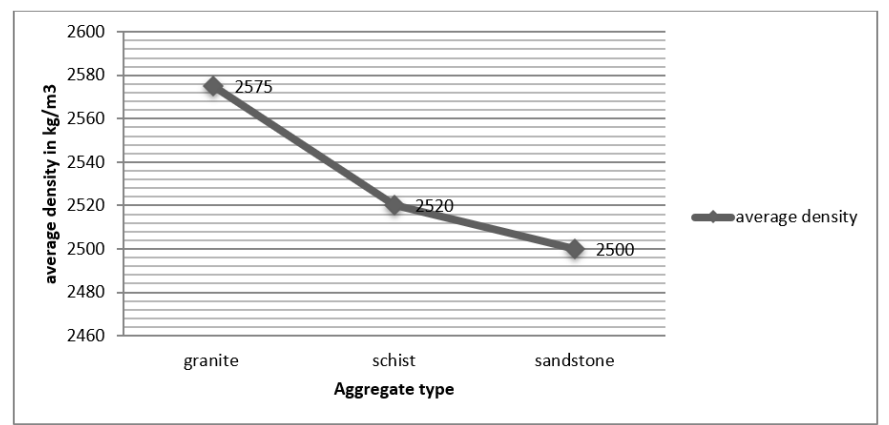

Figure 7 - The average density of concrete cubes produced using the different types of aggregates

Table 11 - Density of concrete cubes $\left(\mathrm{Kg} / \mathrm{m}^{3}\right)$

\begin{tabular}{|l|c|c|c|c|c|}
\hline $\begin{array}{l}\text { Aggregate } \\
\text { type }\end{array}$ & 7 days & 14 days & 21 days & 28 days & $\begin{array}{c}\text { Average } \\
\text { density }\end{array}$ \\
\hline Granite & 2600 & 2533.33 & 2600 & 2533.33 & 2575 \\
\hline Schist & 2483.33 & 2483.33 & 2433.33 & 2450 & 2520 \\
\hline Sandstone & 2566.67 & 2450 & 2333.33 & 2566.67 & 2500 \\
\hline
\end{tabular}

\section{Splitting tensile strength test for concrete cylinders}

The split tensile strength for 7, 14 and 28 days was determined for the concrete cylinders, as shown in the graph below. The results further certify the aggregate types' influence on the concrete's tensile strength development, and it was found to be within the range of the desired design strength by IS 5816 (1999).

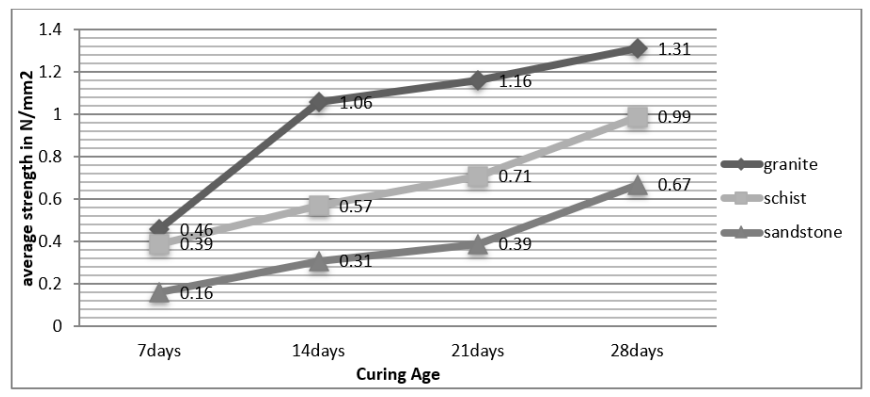

Figure 8 - The average split tensile strength at different curing ages

Table 12 - Split tensile strength of concrete cylinders $\left(\mathrm{N} / \mathrm{mm}^{2}\right)$

\begin{tabular}{|l|c|c|c|c|}
\hline Aggregate type & 7 days & $\begin{array}{c}14 \\
\text { days }\end{array}$ & $\begin{array}{c}21 \\
\text { days }\end{array}$ & $\begin{array}{c}28 \\
\text { days }\end{array}$ \\
\hline Granite & 0.46 & 1.06 & 1.16 & 1.31 \\
\hline Schist & 0.39 & 0.57 & 0.71 & 0.99 \\
\hline Sandstone & 0.16 & 0.31 & 0.39 & 0.67 \\
\hline
\end{tabular}

\section{The density of concrete cylinders}

The density of the concrete cylinders was obtained by weighing 3 of the samples produced for each aggregate (ASTM C 138 [23]). The pieces were removed from the curing tank and left the surface dry for 30 minutes before weighing. The average weight of the sample was then taken, and the result is as shown below.

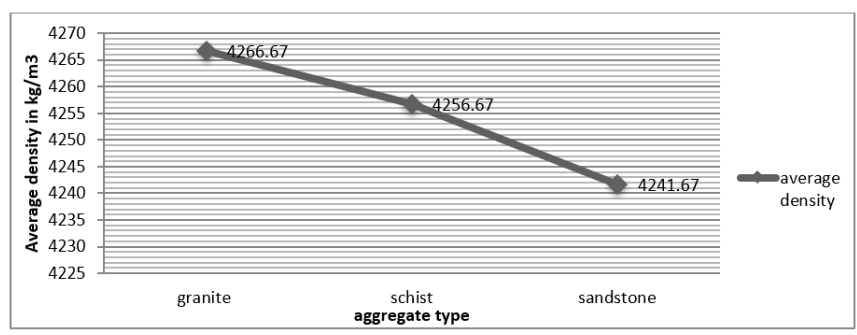

Figure 9 - Showing the average density of concrete cylinders produced using the different types of aggregates 
Table 13 - Density of concrete cylinders $\left(\mathrm{Kg} / \mathrm{m}^{3}\right)$

\begin{tabular}{|l|l|l|l|l|l|}
\hline $\begin{array}{l}\text { Aggregate } \\
\text { type }\end{array}$ & 7 days & 14 days & 21 days & 28 days & $\begin{array}{l}\text { Average } \\
\text { density }\end{array}$ \\
\hline Granite & 4266.67 & 4266.67 & 4266.67 & 4266.67 & 4266.67 \\
\hline Schist & 4366.67 & 4133.33 & 4166.67 & 4366.67 & 4256.67 \\
\hline
\end{tabular}

\begin{tabular}{|l|l|l|l|l|l|l|l|}
\hline Sandstone & 4366.67 & 4066.67 & 4166.67 & 4366.67 & 4241.67 \\
\hline
\end{tabular}

\section{CONCLUSIONS}

This study has been established to calculate the optimum strength achieved using different coarse aggregates, $15 \mathrm{~N} / \mathrm{mm}^{2}$. The tested properties were slump test (workability), compressive forces at 7, 14, 21 and 28 days ages, and splitting tensile strength. The study utilized cement of the same power, coarse aggregate of the maximum size $20 \mathrm{~mm}$, the same water/cement ratio (0.5), and concrete mix (1:2:4) to determine the influence of aggregate type on concrete strength. The results of the tests are reported. Specimens were tested in compression and split tensile using a universal testing machine.

The study results revealed that changing aggregate type can alter the mechanical properties of concrete both at the fresh and hardened stages. The following concluding remarks were made based on the results obtained.

1. The compressive strength of concrete was found slightly above the mix design target for granite and schist but decreased for sandstone aggregate.

2 . The factors that accounted for the variation in the strength of the concrete are attributed to the properties of the individual aggregates (densities and compressive forces) due to different properties and powers.

3. The aggregate from granite have less water absorption ability making it highly workable, while aggregates from sandstone have high water absorption ability, thereby having less workability

4. The splitting tensile strength of the concrete cylinders was found slightly high for granite and schist but decreased for sandstone aggregate.

5. From the impact test result, aggregate from granite and schist can be categorized as solid aggregate, while sandstone can be classified as weak aggregate.

\section{RECOMMENDATIONS}

1. Since changing aggregate type alter concrete properties. As the next step for future research, consideration should be given to examining the influence of these aggregates on a concrete mixture using different water-cement ratios.

2. The properties of the aggregates in view should be determined to ascertain their chemical contents.

3. Other aggregate types should be studied to select coarse aggregate types for different construction work.

We are studying the effects of the coarse aggregate used on other properties of concrete apart from the ones presented in the research.

\section{REFERENCES}

1. Ajagbe, W. O., Tijani, M. A. (2016). Assessment of concrete aggregates in Ibadan, Nigeria. Retrieved from https://www.researchgate.net/publication/319245261_ASSESSMENT_OF_CONCRETE_AGGREG ATES_IN_IBADAN_NIGERIA

2. Beshr, H., Almusallam, A. ., \& Maslehuddin, M. (2003). Effect of coarse aggregate quality on the mechanical properties of high strength concrete. Construction and Building Materials, 17(2), 97103. doi: 10.1016/s0950-0618(02)00097-1

3. Akinleye, M. T., \& Tijani, M. A. (2018). Assessment of Quality of Asphalt Concrete used in Road Construction in South West Nigeria. Nigerian Journal of Technological Development, 14(2), 52. doi: $10.4314 /$ njtd.v14i2.3

4. Ede, A. N. (2011). Measures to reduce the high incidence of structural failures in Nigeria. Journal of Sustainable Development in Africa, 13(1), 153-161.

5. Ede, A. N. (2010). Building collapse in Nigeria: the trend of casualties in the last decade (2000-2010). International Journal of Civil \& Environmental Engineering, 10(6), 32-42.

6. Abdullahi. (2012). Effect of aggregate type on Compressive strength of concrete. International Journal of Civil and Structural Engineering, 2(3). doi: 10.6088/ijcser.00202030008 
7. Wu, K.-R., Chen, B., Yao, W., \& Zhang, D. (2001). Effect of coarse aggregate type on mechanical properties of high-performance concrete. Cement and Concrete Research, 31(10), 1421-1425. doi: 10.1016/s0008-8846(01)00588-9

8. Meddah, M. S., Zitouni, S., \& Belâabes, S. (2010). Effect of content and particle size distribution of coarse aggregate on the compressive strength of concrete. Construction and Building Materials, 24(4), 505-512. doi: 10.1016/j.conbuildmat.2009.10.009

9. Ajagbe, W. O., Tijani, M. A., Arohunfegbe, I. S., \& Akinleye, M. T. (2018). Assessment of fine aggregates from different sources in Ibadan and environs for concrete production. Nigerian Journal of Technological Development, 15(1), 7. doi: 10.4314/njtd.v15i1.2

10. Shetty, M. S. (2005). Concrete technology theory and practice (6th ed.). New Delhi: Chand and Company Limited.

11. Neville, A. M. (2011). Properties of concrete (5th ed.). London: Pearson Education Limited.

12. Lian, C., \& Zhuge, Y. (2009). Investigation of the effect of aggregate on the performance of permeable concrete. London: Taylor \& Francis Group.

13. Ćosić, K., Korat, L., Ducman, V., \& Netinger, I. (2015). Influence of aggregate type and size on properties of pervious concrete. Construction and Building Materials, 78, 69-76. doi: 10.1016/j.conbuildmat.2014.12.073

14. Jain, A. K., \& Chouhan, J. S. (2011). Effect of shape of aggregate on compressive strength and permeability properties of pervious concrete. International Journal of Advanced Engineering Research Studies, 1(1), 120-126.

15. Quayson, J. H., Mustapha, Z. (2019). Impact of coarse aggregate on compressive strength of concrete. Built Environment Journal, 16(1), 49-58.

16. Vilane, B., Sabelo, N. (2016). The Effect of Aggregate Size on the Compressive Strength of Concrete. Journal of Agricultural Science and Engineering, 2(6), 66-69.

17. Rahman, S., Farnaz, T., \& Islam, T. (2019). Experimental investigation of concrete by partial replacement of sand with red soil. Retrieved from

https://www.researchgate.net/publication/330683185_Experimental_Investigation_of_Concret e_by_Partial_Replacement_of_Sand_with_Red_Soil

18. British Standard Specification. (1983). BS 1881: Testing Concrete - part 122: Method for determination of water absorption. London.

19. British Standard Specification. (2002). BS EN 12390: Testing Hardened Concrete - Part 2: Making and Curing Specimens for Strength Tests. London.

20. British Standard Specification. (2000). BS EN 12350: Testing of Fresh - Part 2: Concrete: Method for determination of Slump. London.

21. British Standard Specification. (1983). BS 1881: Part 102: Method for determination of Slump. London.

22. British Standard Specification. (2000). BS EN 12390: Testing Hardened Concrete - Part 3: Compressive Strength of Test Specimens. London.

23. ASTM International West Conshohocken. (2011). ASTM C138: Standard test method for density (Unit Weight), Yield and Air Content (Gravimetric) of Concrete. 